\title{
DIRETRIZES PARA PREVENIR PROBLEMAS EM PROCESSOS DE TRANSFERÊNCIA DE TECNOLOGIA: ESTUDO DE CASO BRASIL-MÉXICO
}

\section{GUIDELINES FOR PREVENTING PROBLEMS IN TECHNOLOGY TRANSFER PROCESSES: A BRAZILIAN-MEXICAN CASE STUDY}

\author{
Fabio R. Mandello Rodrigues *E-mail: abiormr@utfpr.edu.br \\ Carla Estorilio "E-mail: amodio@utfpr.edu.br \\ *Universidade Tecnológica Federal do Paraná (UTFPR), Pato Branco,PR
}

Resumo: A literatura apresenta análises relacionadas a um processo de transferência de tecnologia (PTT), porém, existe pouco material sobre a prevenção dos impactos desse tipo de processo. PTTs entre empresas de países desenvolvidos para países em desenvolvimento tendem a apresentar dificuldades, porém, entre países em desenvolvimento esse processo é ainda mais difícil, com pouco recurso para suportar os procedimentos envolvidos. Esse artigo propõe um conjunto de diretrizes preventivas para minimizar os problemas resultantes de um PTT entre empresas industriais da América Latina. Para isso, é feito um levantamento bibliográfico sobre os PTTs entre indústrias, visando identificar as variáveis que influenciam esse tipo de processo. Com o objetivo de focar na América Latina e identificar os fatores de impacto nesse tipo de PTT, o trabalho apresenta um estudo de caso onde ocorre a transferência de tecnologia de uma empresa brasileira para uma filial situada no México. Posteriormente, utiliza esse mesmo caso para simular a aplicação das diretrizes propostas, com o objetivo de testá-las. O trabalho contribui com onze diretrizes que visam minimizar 14 variáveis, identificadas como impactantes em um PTT. Após a aplicação dessas diretrizes, constatou-se que a indústria poderia ter reduzido os seus gastos e atendido melhor o cliente local, se esta tivesse utilizado essas diretrizes antes de iniciar esse PTT.

Palavras-chave: Transferência de tecnologia. Estudo de Caso Industrial. Melhoria de processo. América Latina. Indústria de Manufatura.

Abstract: While there are various analyses of technology transfer processes (TTPs) in the literature, there is a dearth of guidelines to help prevent the impacts associated with such processes. TTPs between companies in developed countries and developing countries frequently encounter difficulties, and the process is even more difficult between companies in developing countries, which have limited resources to support the procedures involved. We propose a set of preventive guidelines to minimize the problems arising from a TTP between industrial companies in Latin America. To this end, the literature about TTPs between companies and the variables that affect such processes is reviewed. In order to focus on Latin America and identify the factors that have an impact on this type of TTP, we describe a case study involving technology transfer from a Brazilian company to a subsidiary in Mexico. This same case is then used to simulate the use of the proposed guidelines in order to validate them. We put forward eleven guidelines that seek to minimize the 14 variables identified as having an impact on a TTP. Once these guidelines were applied, it was observed that the company tended to reduce its costs and provide a better service for its local customers in the country to which the technology was transferred.

Keywords: Technology transfer strategy. Industrial case study. Latin American. Industrial Process Improvement. Manufacturing Industry. 


\section{INTRODUÇÃO}

Com a globalização de conhecimentos e uniformidade de mercados, muitas empresas buscam ampliar as suas atividades comerciais e produtivas para outras regiões, sejam dentro do país ou fora dele. Há também o interesse de empresas na formação de consórcios produtivos, onde empresas trabalham em conjunto sob metas comuns, visando ganhar competitividade (CARVALHO et al., 2007). Tais situações são normalmente efetivadas através de uma Transferência de Tecnologia (TT).

A TT é necessária para que uma nova unidade produtiva funcione de maneira eficiente e eficaz, afinal, segundo Gallaher e Delhotal (2005), a difusão de informação e tecnologia é a chave para a redução de custos produtivos, principalmente em países em desenvolvimento. Gurr et al. (1998) também ressalta a importância da TT para o aumento da qualidade de vida em indústrias de países em desenvolvimento. Segundo o autor, a prática de se transferir tecnologia no campo da ergonomia facilita a rápida melhora da qualidade de vida e ajuda a reduzir desperdícios de recursos escassos em países mais pobres.

Em função desses ganhos, pode-se afirmar que a tecnologia vem se tornando um elemento determinante na competitividade entre empresas, o que reforça a importância de se ter um processo de TT planejado e estruturado (Hemais et al., 2005). Essa questão é reforçada por Farooq and O'brien (2009), através de um estudo realizado junto à indústria aeroespacial. Eles afirmam que as variáveis presentes em um PTT devem ser avaliadas, considerando a estratégia e os objetivos da empresa, com o objetivo de evitar dificuldades que podem comprometer a qualidade do produto final. Jiang (2006) também mostra uma preocupação sobre a necessidade de se conhecer analiticamente os fatores, barreiras e variáveis presentes em um PTT. Em um estudo de caso, o autor apresenta as mudanças do PTT ocorridas na China após a sua expansão industrial, considerando a distribuição e influência de diferentes países que transferiram tecnologia para regiões distintas do território chinês.

Albino, Garavelli e Schiuma (1999) abordam a transferência de conhecimento entre a empresa matriz e seus fornecedores, ressaltando os cuidados e restrições Revista Produção Online, Florianópolis, SC, v.12, n. 4, p. 944-971, out./dez. 2012. 
que devem existir para que a empresa não comprometa a sua competitividade, em função da abertura excessiva de conhecimentos importantes.

Algumas estratégias para apoiar o PTT entre empresas industriais vêm sendo apresentadas nos últimos anos. Destas, pode-se citar as propostas por Argabright (1999), Cohen (2004), ICS Unido (2005), Rogers (2002) e Zenner (2001). Petroni e Verbano (2000) também apresentam uma estratégia para desenvolver e transferir tecnologia, porém, com foco na indústria aeroespacial. Entretanto, apesar delas acrescentarem análises importantes sobre um PTT, elas não apresentam diretrizes que auxiliem a identificar os fatores e variáveis que impactam em um PTT.

Sendo assim, esse artigo apresenta um conjunto de diretrizes de apoio para se transferir tecnologia entre empresas da mesma organização ou entre organizações diferentes, com sedes em diferentes locais, regiões ou países, com foco nos países em desenvolvimento. O objetivo é a prevenção de impactos negativos que possam surgir ao longo deste processo, gerando prejuízos ou impedindo uma TT efetiva.

Para realizar essa pesquisa, além da revisão bibliográfica, foi realizado um estudo de caso para analisar um PTT entre empresas de uma mesma organização, sendo a matriz situada no Sul do Brasil e a nova filial instalada no México entre 2007 e 2008.

\section{O PROCESSO DE TRANSFERÊNCIA DE TECNOLOGIA}

Antes de abordar o tema PTT, é importante compreender a definição da tecnologia a ser transferida. Etimologicamente, a palavra "tecnologia" possui origens do grego, "techne", significando arte, técnica ou habilidade, e do Indo-Europeu, "teks", significando tecer ou fabricar. Dessa forma, constata-se que a tecnologia pode ser considerada um elemento cultural, considerando a capacidade do homem de criar tecnologia (CYSNE, 2005).

Segundo Heslop et al. (2001), a tecnologia por si só não gera riqueza, é a sua aplicação que pode gerar inovações e invenções. Afinal, conforme Lundquist (2003), a tecnologia é o resultado tangível da ciência com a engenharia. 
Cohen (2004) afirma que a tecnologia é um fator chave para a promoção de uma produção eficiente e para uma contínua melhoria dos sistemas econômicos e técnicos. Segundo o autor, a tecnologia vem sendo classificada em função da sua aplicação, base do conhecimento, organização e outros fatores. O conceito de tecnologia adotado nesse artigo corresponde à tecnologia empregada nas indústrias para se produzir algum bem, seja ele na forma de máquinas, instalações, equipamentos e/ou conhecimentos.

Para Meshkati (1989), transferir tecnologia é um dos mais importantes processos de geração de bens de produção e serviços, além de um processo base para o desenvolvimento de um país.

De acordo com Wisner (1994), a TT é definida como "um elemento essencial do comércio internacional e das relações entre os diferentes países". Afinal, a TT é algo abrangente que envolve transferência de máquinas, produtos, conhecimentos e procedimentos nas diversas áreas: indústria, saúde, educação e alimentação. Esse trabalho, em especial, foca a TT industrial.

De acordo com Takahashi (2005), a TT pode ser definida como um processo realizado entre duas entidades sociais em que o conhecimento tecnológico é adquirido, desenvolvido, utilizado e melhorado por meio da transferência de um ou mais componentes da tecnologia.

Kremic (2003) aborda a TT como sendo um processo entre um emissor de tecnologia e um receptor, onde há pontos de controle que o direcionam, tais como: o início do processo, o processo em si, o final do processo e uma avaliação final de todo o procedimento para mostrar como o mesmo foi executado. Visando compreender esse processo, é importante identificar as variáveis e barreiras envolvidas em um PTT.

\subsection{Variáveis e barreiras em um PTT}

Wisner (1994) apresenta uma análise, relacionando variáveis que impactam em um PTT. As variáveis estão divididas em quatro grupos que se relacionam às condições geográficas e econômicas, aos limites comerciais e financeiros e ao tecido industrial e social.

Revista Produção Online, Florianópolis, SC, v.12, n. 4, p. 944-971, out./dez. 2012. 
Abeyseakera (1990) também identifica algumas variáveis a serem consideradas em um PTT. São elas: fornecimento energético, clima, renda, condições econômicas e transporte público.

Dutra (1999) apresenta um conjunto de doze variáveis que estão relacionadas ao emissor e ao receptor de tecnologia. As variáveis são: localização, demografia, tecnologia, situação político-econômica, meios de transporte e de comunicação, assistência médica, temperatura, produto interno bruto, índice de desenvolvimento humano, educação, fatores industriais e ambiente social/profissional.

O Quadro 1 apresenta um resumo das variáveis encontradas na literatura, consideradas em um processo de transferência de tecnologia, sendo estas agrupadas em três categorias. Tal agrupamento foi efetuado através da identificação da ação de cada variável nos aspectos sócio econômicos, geográficos e técnicos industriais, considerando a visão de três autores e a análise dos autores desse trabalho. No Quadro 1 é possível observar oito variáveis comuns entre os autores, as quais parecem ser importantes em uma TT, demandando averiguação em um estudo de caso prático. 
Quadro 1 - Comparação entre as variáveis para TT

\begin{tabular}{|c|c|c|c|}
\hline Autores (ano) & Abeyseakera (1990) & Wisner (1994) & Dutra (1999) \\
\hline \multicolumn{4}{|l|}{$\begin{array}{l}\text { Categorias de } \\
\text { variáveis }\end{array}$} \\
\hline \multirow{9}{*}{ Sócio econômica } & $\begin{array}{l}\text { Renda e condições } \\
\text { econômicas }\end{array}$ & Limites financeiros & \\
\hline & Educação & & Educação \\
\hline & $\begin{array}{l}\text { Ambiente social e } \\
\text { profissional }\end{array}$ & & Ambiente social e profissional \\
\hline & Religião & & \\
\hline & Aspectos políticos & Fatores sociais & Situação Política \\
\hline & & $\begin{array}{l}\text { Condições } \\
\text { econômicas }\end{array}$ & Condições econômicas \\
\hline & & & Assistência médica \\
\hline & & & $\begin{array}{l}\text { Índice de desenvolvimento } \\
\text { humano }\end{array}$ \\
\hline & & & Produto interno bruto \\
\hline \multirow{8}{*}{ Geográfica } & Fornecimento Energético & & \\
\hline & Clima & & Temperatura \\
\hline & Transporte público & & Meios de transporte \\
\hline & $\begin{array}{l}\text { Habilidades regionais } \\
\text { especiais }\end{array}$ & & \\
\hline & & $\begin{array}{l}\text { Condições } \\
\text { geográficas }\end{array}$ & \\
\hline & & & Meios de comunicação \\
\hline & & & Localização \\
\hline & & & Demografia \\
\hline \multirow{3}{*}{$\begin{array}{l}\text { Industriais e } \\
\text { técnicas }\end{array}$} & & Fatores industriais & Fatores industriais \\
\hline & & Limites comerciais & \\
\hline & & & Tecnologia \\
\hline
\end{tabular}

Além das variáveis que impactam em um PTT, há barreiras que influenciam o mesmo. Essas barreiras são divididas em três categorias, conforme Greiner e Franza (2003): barreiras tecnológicas, regulatórias (ligadas às leis regionais do receptor de tecnologia) e humano-sociais.

As barreiras tecnológicas estão relacionadas aos fatores que impedem e interferem na funcionalidade, operacionalidade e manutenção da tecnologia em seu ambiente receptor. Em função disso, Rahman and Bennett (2009) ressaltam a importância de se analisar e selecionar parceiros com bom domínio da tecnologia demandada. Afinal, uma falha nessa seleção poderia constituir um obstáculo para o sucesso da TT. Frank e Echeveste (2011) abordam a transferência de conhecimento 
(TC), considerada como parte da barreira tecnológica, a qual também pode comprometer negativamente o desenvolvimento de produtos.

As barreiras regulatórias dizem respeito aos procedimentos e leis governamentais e ocorrem quando a tecnologia transferida requer especificações exigidas pela região alvo que, em geral, não coincidem com as regulamentações de origem.

As barreiras humano-sociais têm sido as principais geradoras de dificuldades a serem superadas em um PTT, sendo a categoria mais impactante e de difícil gestão. Elas surgem quando as pessoas envolvidas na TT não estão preparadas para lidar com a nova tecnologia. Essa barreira foi analisada por Jabar et al. (2010), os quais investigaram as influências do aprendizado em um PTT. Para eles, o aprendizado não só impacta na habilidade de se absorver a tecnologia, como também, pode comprometer alianças estratégicas, essencial para o sucesso da TT.

Erensal e Albayrak (2007) sintetizam as variáveis previamente comentadas, classificando-as em dois grandes grupos: as macro ergonômicas (relacionadas à infra estrutura) e as micro ergonômicas (relacionadas às variáveis culturais e organizacionais).

O Quadro 2 mostra uma síntese das principais barreiras presentes em um PTT, conforme Greiner e Franza (2003).

Quadro 2 - Principais fatores que geram barreiras para a TT.

\begin{tabular}{|c|l|}
\hline & A Falta de regulamentações que definam o uso da tecnologia. \\
A Tempo extenso para adequação às normas locais. \\
Tecnológicas & A Riscos técnicos. \\
& $\begin{array}{c}\text { A Pouco detalhamento das necessidades e características referentes à } \\
\text { tecnologia a ser transferida; }\end{array}$ \\
& A Falhas de origem técnica relacionadas aos fornecedores, máquinas, \\
& equipamentos, instruções de operação e manutenção.
\end{tabular}


As variáveis apresentadas no Quadro 01 podem originar fortes barreiras para o sucesso de um PTT. Tais barreiras estão relacionadas e divididas conforme 0 Quadro 02. Portanto, um dos objetivos principais da análise das variáveis presentes em um PTT (Quadro 01) é evitar o surgimento de barreiras que comprometam o PTT (Quadro 02).

\section{MÉTODO DE PESQUISA}

A pesquisa iniciou com um levantamento bibliográfico, abordando PTTs entre indústrias e as variáveis que influenciam positivamente e negativamente esse tipo de procedimento. Posteriormente, visando identificar variáveis presentes em casos de PTT entre países em desenvolvimento, realizou-se uma análise em campo, entre duas indústrias situadas na América Latina (Brasil/emissora - México/receptora). As variáveis identificadas na literatura e em campo foram organizadas com o objetivo de delimitar os impactos eminentes em um PTT entre países em desenvolvimento. Através da análise das variáveis e seus impactos, foram sugeridos meios de minimizá-las ou contorná-las e, se impossível, considerá-las problemas previsíveis nesse tipo de procedimento.

Considerando o fato de que um dos autores estava inserido no PTT das empresas estudadas, acompanhando os procedimentos desde o seu início, pode-se dizer que esse estudo de campo classifica-se como uma "Pesquisa-Ação". Segundo Thiollent (1997), a pesquisa-ação é um tipo de pesquisa social com base empírica que é concebida e realizada em estreita associação com uma ação ou com a resolução de um problema coletivo, no qual o pesquisador e os participantes representativos da situação estão envolvidos de modo cooperativo ou participativo.

A pesquisa-ação é um método de condução de pesquisa aplicada, orientada para a elaboração de diagnósticos, identificação de problemas e busca de soluções, como é o caso desta pesquisa, onde se pretende diagnosticar os problemas decorrentes de um PTT e buscar soluções que atendam a demanda industrial nesse tipo de procedimento. Além disso, a pesquisa ação permite que o pesquisador teste, posteriormente, as soluções sugeridas, implementando e acessando as mudanças no cenário real (LINDGREN et al., 2004), em consonância com o objetivo dessa 
pesquisa. Esse perfil de estudo também contribui para a coleta de dados, pois, segundo Eden e Huxham (2001), em virtude da ampla inserção do pesquisador no contexto da pesquisa e do envolvimento do pesquisador e dos membros da organização pesquisada em torno de um interesse comum, os dados tornam-se acessíveis.

Para o desenvolvimento dessa pesquisa-ação, seguiu-se a dinâmica sugerida por Stringer (1996), que compreende três ações: observar, para reunir informações e construir um cenário; pensar, para explorar, analisar e interpretar os fatos; e agir, implantando e avaliando as ações. Para conduzir a pesquisa, quatro etapas foram desenvolvidas, conforme Thiollent (1997): exploratória, planejamento, ação e avaliação. As quatro são descritas abaixo, visando apresentar como cada fase foi desenvolvida nesse caso:

1. Fase Exploratória: envolve a definição do pesquisador e de suas relações, a explanação sobre os objetivos do estudo e a metodologia empregada e, por último, a realização de pesquisa de campo de caráter diagnóstico, visando detectar os principais problemas existentes.

Essa fase envolveu a análise do PTT, desde o seu início, entre a empresa matriz brasileira e a sede receptora de tecnologia recém instalada no México. A seleção, referente às duas empresas industriais, deveu-se ao fato de um dos pesquisadores participar deste processo desde o seu início, sendo o principal responsável por esse PTT. Nesse primeiro momento, os métodos de investigação envolveram consulta a documentos históricos e aos relacionados aos trâmites referentes à TT, além de entrevistas semi estruturadas com os funcionários envolvidos no PTT nas duas empresas. Os funcionários envolvidos eram engenheiros, trabalhadores do setor fabril, administradores, supervisores, gerentes e diretores da matriz brasileira e da sede no México. Entre os fatores coletados e observados estão: as variáveis sociais, geográficas e industriais que impactam em um PTT, além daquelas que tendem a obstruir esse tipo de procedimento, como as de origem tecnológica, regulatória e humano-social, conforme previamente apresentado na revisão desse trabalho. 
2. Fase de Planejamento: envolve a coleta de dados, análise dos dados coletados, diagnóstico da situação, compartilhamento dos resultados encontrados e sugestão para melhorias.

Nessa fase buscou-se identificar, além das variáveis que permeiam um PTT, os impactos gerados por estas, visando selecionar e destacar aquelas com impactos diretos e negativos nos procedimentos, as quais afetariam fortemente a eficácia do PTT. Isso ocorreu através de debates coletivos realizados em seminários na empresa situada no México. Esse procedimento conduziu à elaboração de um quadro de diretrizes para que essas variáveis fossem bem conduzidas, visando um PTT eficaz. Isso estava em consonância com a meta da empresa matriz, que visava ter um produto competitivo no mercado norte americano, com custos abaixo do mercado brasileiro e com qualidade igual ou superior à matriz, através de uma TT para uma nova unidade situada no México. No início dessa nova experiência, a tecnologia transferida do Brasil para o México passaria por uma série de procedimentos, os quais ainda eram desconhecidos para a empresa matriz naquele momento inicial, cujas consequências finais só seriam dominadas depois de concluído o PTT, com o devido custo relacionado aos problemas que viessem a surgir durante esse processo. Sendo assim, focou-se em coletar dados relacionados aos vários itens que seriam transferidos, como máquinas, equipamentos, manuais e outros recursos tecnológicos, observando, em paralelo, a influência de fatores como a logística, aspectos políticos/regulatórios, sociais e outros previamente citados. A elaboração de diretrizes para minimizar os impactos negativos ocasionados por algumas variáveis identificadas no PTT estudado foram desenvolvidas pelos pesquisadores, em conjunto com o grupo participante da empresa, respaldadas nas revisões bibliográficas.

3. Fase de ação: envolve a difusão de resultados e definição de objetivos alcançáveis por meio de ações concretas, a apresentação de propostas e a implantação de ações-piloto que, após avaliação, poderiam ser assumidas sem a atuação dos pesquisadores.

Nesse estudo houve somente a "simulação da implantação das diretrizes elaboradas" na fase anterior, considerando os impactos diferenciais no PTT se estas Revista Produção Online, Florianópolis, SC, v.12, n. 4, p. 944-971, out./dez. 2012. 
tivessem sido aplicadas ou consideradas antes do início do PTT. Isso aconteceu porque o PTT já havia ocorrido quando o estudo foi concluído e não haveria a possibilidade de iniciar um novo processo; as diretrizes serviriam apenas para uma nova situação de TT entre empresas de perfil similar.

4. Fase de Avaliação: consiste em verificar os resultados das ações no contexto organizacional da pesquisa e suas consequências a curto e médio prazo, extraindo 0 aprendizado para utilizá-lo em estudos futuros.

Para avaliar a simulação da aplicação das diretrizes foi utilizado como critério o diferencial do desempenho em vários procedimentos envolvidos na transferência de tecnologia, comparando o que já havia acontecido durante o PTT previamente concluído, com o que aconteceria com a consideração prévia das variáveis identificas e seus impactos, considerando as diretrizes para contornar ou evitar tais impactos. O desempenho foi avaliado quanto ao comprometimento do tempo, custo e qualidade das resultantes de cada fase do PTT, considerando procedimentos, serviços e produtos físicos.

\section{VARIÁVEIS DO PTT DETECTADAS EM CAMPO INDUSTRIAL}

O estudo de campo iniciou com a Fase Exploratória, quando se definiu o pesquisador e suas relações dentro do grupo que atuaria no PTT. O grupo de ambas as empresas foram comunicados sobre o estudo e a metodologia que seria empregada. Em seguida, o estudo iniciou, juntamente com o início da unidade recém instalada no México, com a presença constante do pesquisador brasileiro, o qual permaneceu na nova unidade durante todo o processo.

A empresa brasileira iniciou um PTT para uma nova unidade instalada no México, envolvendo tecnologias relacionadas às câmaras frias e salas limpas para laboratórios. A unidade brasileira é uma empresa de grande porte, instalada no Brasil há aproximadamente 30 anos, de origem Sueca, e a nova unidade se enquadra como uma empresa de médio porte, a qual iniciou suas atividades em 2007. Ambas possuem atividades relacionadas ao projeto, fabricação e venda de produtos industriais.

Revista Produção Online, Florianópolis, SC, v.12, n. 4, p. 944-971, out./dez. 2012. 
Em seguida, foi iniciada a Fase de Planejamento, envolvendo coleta de dados em ambas as empresas. Para isso, além de observações e acompanhamento de trâmites relacionados às transferências de tecnologias da matriz para a filial, permitindo identificar as variáveis regulatórias, envolvendo trâmite de maquinários, projetos e outros, também foram coletadas informações através de questionários semi estruturados com alguns funcionários da matriz e da filial. Com alguns dados coletados, alguns seminários foram realizados na filial, visando compreender as particularidades do país, relacionadas aos fatores sócio econômicos, geográficos e técnicos industriais.

Após a coleta, as variáveis foram agrupadas nessas três categorias, resultando em vinte e quatro variáveis, as quais podem ser vistas no Quadro 3. Algumas variáveis foram provenientes da literatura e outras foram identificadas em campo. Nessa tabela também foram assinaladas se o impacto era considerado direto e de relevância, segundo os funcionários envolvidos e os entrevistados, ou se a variável exercia um impacto de baixa relevância no contexto do desempenho do PTT. 
Quadro 3 - Grau de importância das variáveis em um PTT para os impactos diretos e indiretos

\begin{tabular}{|c|c|c|}
\hline $\begin{array}{l}\text { Tipos de } \\
\text { variáveis }\end{array}$ & Variáveis (Indicadores) & $\begin{array}{c}\text { Com maior impacto } \\
\text { no PTT }\end{array}$ \\
\hline \multirow{4}{*}{ 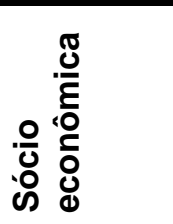 } & 1. Custos industriais & $\mathrm{X}$ \\
\hline & 2. Educação & $\mathrm{X}$ \\
\hline & 3. Ambiente profissional & \\
\hline & 4. $\quad$ Aspectos religiosos & \\
\hline \multirow{7}{*}{ 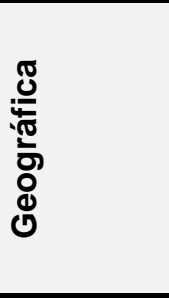 } & 5. Normas e regulamentações da região & $\mathrm{X}$ \\
\hline & 6. Suprimento energético & $\mathrm{X}$ \\
\hline & 7. Idioma & $\mathrm{X}$ \\
\hline & 8. Mão de obra (cultura local) & $\mathrm{X}$ \\
\hline & 9. $\quad$ Clima & \\
\hline & 10. Transporte público & \\
\hline & 11. Trânsito, ruas e rodovias & \\
\hline \multirow{13}{*}{ 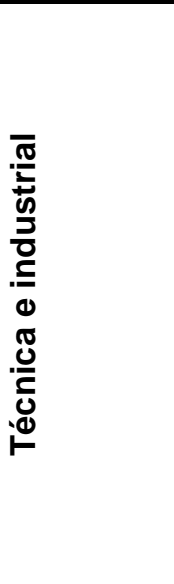 } & 12. Qualidade industrial & $\mathrm{X}$ \\
\hline & 13. Logística interna & $\mathrm{X}$ \\
\hline & 14. Logística externa & $\mathrm{X}$ \\
\hline & $\begin{array}{l}\text { 15. Rede local de fornecedores (capacidade } \\
\text { técnica) }\end{array}$ & $\mathrm{X}$ \\
\hline & 16. Infra estrutura fabril & $\mathrm{X}$ \\
\hline & 17. Controle de estoque & $\mathrm{X}$ \\
\hline & 18. Engenharia de processos & $\mathrm{X}$ \\
\hline & 19. Especificações de projeto de produto & $\mathrm{X}$ \\
\hline & 20. Segurança do trabalho & \\
\hline & 21. Manutenção industrial & \\
\hline & 22. Gestão industrial & \\
\hline & 23. Tecnologia da informação & \\
\hline & 24. Espaço físico e arranjo fabril & \\
\hline
\end{tabular}

É importante observar que algumas variáveis, apesar de importantes, são facilmente transferidas e gerenciadas e, portanto, não foram assinaladas como preocupantes em uma situação de PTT. Outras variáveis, típicas da região, poderiam ou não ter um efeito mais incisivo no PTT, porém, nesse caso, foram consideradas de baixo impacto porque não geraram problemas, como por exemplo: o clima, a estrutura rodoviária, o transporte público e os aspectos religiosos. Porém, é importante salientar que todos os itens devem ser verificados quando a TT ocorrer entre países com situações diferentes deste estudo, quando as variáveis consideradas de baixa relevância poderiam impactar fortemente em outra situação de PTT. Um exemplo poderia ser a TT do Brasil para a Índia; apesar de ambos os países serem considerados países em vias de desenvolvimento, seus climas, estruturas de transporte e religião poderiam causar forte impacto em algumas TTs. 
Após a identificação e análise do impacto das variáveis apresentadas no Quadro 3, visou-se compreender a situação de cada uma das quatorze variáveis que apresentaram impacto relevante no PTT das empresas estudadas. O Quadro 4 apresenta a situação relacionada à ambas as empresas no momento do estudo.

Quadro 4 - Situação entre as empresas envolvidas no processo.

\begin{tabular}{|c|c|c|}
\hline $\begin{array}{c}\text { Variável com } \\
\text { impacto relevante no } \\
\text { PTT }\end{array}$ & $\begin{array}{l}\text { Empresa emissora de } \\
\text { tecnologia (Brasil) }\end{array}$ & $\begin{array}{c}\text { Empresa receptora de tecnologia } \\
\text { (México) }\end{array}$ \\
\hline $\begin{array}{l}\text { Custos } \\
\text { industriais }\end{array}$ & $\begin{array}{l}\text { Fortemente relacionados aos salários } \\
\text { e impostos. }\end{array}$ & $\begin{array}{l}\text { Fortemente relacionados à logística, } \\
\text { manutenção, desenvolvimentos de planilhas de } \\
\text { custos, rotatividade de funcionários e } \\
\text { treinamentos. }\end{array}$ \\
\hline Educação & $\begin{array}{l}\text { Alta, com qualificação técnica } \\
\text { representativa entre os funcionários. }\end{array}$ & $\begin{array}{l}\text { De média a baixa, com a maioria dos } \\
\text { funcionários sem qualificação técnica. }\end{array}$ \\
\hline $\begin{array}{l}\text { Normas e } \\
\text { regulamentos } \\
\text { da região }\end{array}$ & $\begin{array}{l}\text { Pouco conhecimento sobre normas } \\
\text { regulatórias do México. }\end{array}$ & $\begin{array}{l}\text { Falta de coordenação com a equipe brasileira } \\
\text { para solucionar problemas operacionais } \\
\text { relacionados aos trâmites regulatórios. }\end{array}$ \\
\hline Suprimento energético & $\begin{array}{l}\text { Corretamente dimensionado para o } \\
\text { Brasil. }\end{array}$ & $\begin{array}{l}\text { Em desenvolvimento para atendimento da } \\
\text { demanda local. }\end{array}$ \\
\hline Idioma & Português & Espanhol \\
\hline $\begin{array}{l}\text { Mão de obra } \\
\text { (cultura local) }\end{array}$ & $\begin{array}{l}\text { Região industrializada, com } \\
\text { universidades e escolas técnicas, com } \\
\text { Mão de obra qualificada. }\end{array}$ & $\begin{array}{l}\text { Região industrializada, porém com poucas } \\
\text { universidades ou escolas técnicas para atender } \\
\text { a demanda da região. }\end{array}$ \\
\hline Qualidade industrial & $\begin{array}{l}\text { Departamento que operacionaliza a } \\
\text { qualidade do produto e do processo, } \\
\text { com engenheiros e técnicos } \\
\text { experientes. }\end{array}$ & $\begin{array}{l}\text { Sem departamento de qualidade estruturado, } \\
\text { contando apenas com as orientações da } \\
\text { empresa emissora de tecnologia. Sem equipe } \\
\text { e/ou funcionários treinados. }\end{array}$ \\
\hline $\begin{array}{l}\text { Logística interna } \\
\text { (México) }\end{array}$ & Departamento logístico estruturado. & $\begin{array}{l}\text { Poucos funcionários com treinamento no Brasil } \\
\text { Equipe com baixa experiência. }\end{array}$ \\
\hline $\begin{array}{l}\text { Logística externa } \\
\text { (Importação/ } \\
\text { Exportação) }\end{array}$ & $\begin{array}{l}\text { Departamento logístico estruturado, } \\
\text { com profissionais experientes. }\end{array}$ & $\begin{array}{l}\text { Poucos funcionários com treinamento no Brasil } \\
\text { Equipe com média experiência. }\end{array}$ \\
\hline $\begin{array}{l}\text { Rede local de } \\
\text { fornecedores }\end{array}$ & Cadeia de fornecedores desenvolvida. & $\begin{array}{l}\text { Cadeia de fornecedores em desenvolvimento, } \\
\text { porém sem qualificação ou certificação } \\
\text { requerida. }\end{array}$ \\
\hline Infra estrutura fabril & $\begin{array}{l}\text { Empresa estruturada devido aos anos } \\
\text { de funcionamento. }\end{array}$ & $\begin{array}{l}\text { Empresa com estrutura física em construção ol } \\
\text { em fase de projeto, sem estrutura necessária } \\
\text { completa. }\end{array}$ \\
\hline Controle de estoque & $\begin{array}{l}\text { Departamento específico com } \\
\text { profissionais experientes. }\end{array}$ & Poucos profissionais e em fase de treinamento. \\
\hline $\begin{array}{l}\text { Engenharia } \\
\text { de processos }\end{array}$ & $\begin{array}{l}\text { Departamento com engenheiros } \\
\text { especializados nas áreas dos } \\
\text { processos envolvidos na produção do } \\
\text { produto comercializado. }\end{array}$ & $\begin{array}{l}\text { Empresa sem esse setor, dependendo de } \\
\text { informações da matriz, com visitas técnicas } \\
\text { esporádicas. }\end{array}$ \\
\hline $\begin{array}{l}\text { Especificações } \\
\text { de projeto } \\
\text { de produto }\end{array}$ & $\begin{array}{l}\text { Departamento com engenheiros na } \\
\text { área de desenvolvimento de produtos. }\end{array}$ & $\begin{array}{l}\text { Informações de projeto provenientes da matriz, } \\
\text { sem a participação de engenheiros ou } \\
\text { fabricantes locais. }\end{array}$ \\
\hline
\end{tabular}

Após a seleção das variáveis mais impactantes nesse PTT e a análise da situação atual nas empresas, foram detalhados os impactos desencadeados através de cada variável, visando identificar as suas causas (Ver Quadro 5).

Revista Produção Online, Florianópolis, SC, v.12, n. 4, p. 944-971, out./dez. 2012. 
Quadro 5 - Impactos das variáveis que mais obstruem um PTT e as suas respectivas causas

\begin{tabular}{|c|c|c|}
\hline $\begin{array}{l}\text { Variável } \\
\text { geradora do } \\
\text { impacto }\end{array}$ & Impactos que obstruem o PTT & $\begin{array}{c}\text { Causas dos impactos que } \\
\text { obstruem o PTT }\end{array}$ \\
\hline $\begin{array}{l}\text { Custos } \\
\text { industriais }\end{array}$ & $\begin{array}{l}\text { Gastos com atividades não previstas } \\
\text { como adequação de máquinas e } \\
\text { equipamentos, adequações fabris, } \\
\text { contratação de técnicos estrangeiros para } \\
\text { instalações fabris e compra de insumos } \\
\text { locais em caráter de emergência. }\end{array}$ & $\begin{array}{l}\text { Falta de previsão e planejamento das reais } \\
\text { demandas do processo produtivo, } \\
\text { considerando, inclusive, o tempo de } \\
\text { importação de insumos a serem enviados } \\
\text { pela matriz. }\end{array}$ \\
\hline Educação & $\begin{array}{l}\text { Parada no funcionamento de tecnologias, } \\
\text { comprometimento da qualidade do } \\
\text { produto e custos com retrabalhos e horas } \\
\text { extras. }\end{array}$ & $\begin{array}{l}\text { Falta de profissionais de nível similar ou } \\
\text { superior ao da empresa emissora de } \\
\text { tecnologia. }\end{array}$ \\
\hline $\begin{array}{l}\text { Normas e } \\
\text { regulamentos da } \\
\text { região }\end{array}$ & $\begin{array}{l}\text { Atrasos na efetivação da tecnologia } \\
\text { transferida e seu desenvolvimento. }\end{array}$ & $\begin{array}{l}\text { Estudo incompleto dos aspectos legais do } \\
\text { local de destino no momento da decisão de } \\
\text { se transferir tecnologia. }\end{array}$ \\
\hline $\begin{array}{l}\text { Suprimento } \\
\text { energético }\end{array}$ & Encarecimento e atraso do PTT. & $\begin{array}{l}\text { Falta de planejamento adequado para } \\
\text { prever as instalações necessárias e a } \\
\text { demanda energética. }\end{array}$ \\
\hline Idioma & $\begin{array}{l}\text { Atrasos, em função do mau } \\
\text { funcionamento de máquinas e } \\
\text { dispositivos, com gastos extras com } \\
\text { adequações de instruções de trabalho, } \\
\text { manutenção e dados técnicos. }\end{array}$ & $\begin{array}{l}\text { Falta de manuais e instruções técnicas no } \\
\text { idioma do receptor da tecnologia. }\end{array}$ \\
\hline $\begin{array}{l}\text { Mão de obra } \\
\text { (cultura local) }\end{array}$ & $\begin{array}{l}\text { Falta de qualidade e atrasos para o } \\
\text { início/desenvolvimento da tecnologia } \\
\text { transferida. Alto índice de absenteísmo } \\
\text { em dias religiosos ou festivos sem prévio- } \\
\text { aviso. }\end{array}$ & $\begin{array}{l}\text { Falta de análise e previsão dos costumes } \\
\text { locais. }\end{array}$ \\
\hline $\begin{array}{l}\text { Qualidade } \\
\text { industrial }\end{array}$ & $\begin{array}{l}\text { Falta de qualidade em produtos enviados } \\
\text { aos clientes. }\end{array}$ & $\begin{array}{l}\text { Falta de gestão da qualidade local, com } \\
\text { procedimentos, planos e profissionais } \\
\text { ligados às diretrizes da matriz. }\end{array}$ \\
\hline $\begin{array}{l}\text { Logística interna } \\
\text { (México) e } \\
\text { Controle de } \\
\text { estoques }\end{array}$ & Atraso no início das operações. & $\begin{array}{l}\text { Falta de recebimento de insumos } \\
\text { necessários para o funcionamento da nova } \\
\text { tecnologia, não considerados previamente } \\
\text { no início do processo. }\end{array}$ \\
\hline $\begin{array}{l}\text { Logística externa } \\
\text { (Importação/ } \\
\text { Exportação) }\end{array}$ & $\begin{array}{l}\text { Atrasos e custos não previstos no } \\
\text { planejamento de encomenda de matéria } \\
\text { prima e máquinas importadas. }\end{array}$ & $\begin{array}{l}\text { Falta de: documentação em tempo hábil, } \\
\text { planejamento adequado das operações e } \\
\text { profissionais tecnicamente qualificados para } \\
\text { demandas específicas. }\end{array}$ \\
\hline $\begin{array}{l}\text { Rede local de } \\
\text { fornecedores }\end{array}$ & $\begin{array}{l}\text { Falta de matéria prima, ferramentas e } \\
\text { serviços locais para o funcionamento da } \\
\text { tecnologia. }\end{array}$ & $\begin{array}{l}\text { Falta de profissionais aptos a localizarem } \\
\text { fornecedores em tempo hábil ou } \\
\text { fornecedores alternativos para máquinas, } \\
\text { equipamentos e insumos para itens críticos. }\end{array}$ \\
\hline $\begin{array}{l}\text { Infra estrutura } \\
\text { fabril }\end{array}$ & $\begin{array}{l}\text { Atrasos e gastos não previstos para o } \\
\text { início da nova tecnologia. }\end{array}$ & $\begin{array}{l}\text { Falta de análise das condições técnicas e } \\
\text { estruturais para o recebimento da tecnologia } \\
\text { no receptor. }\end{array}$ \\
\hline $\begin{array}{l}\text { Engenharia de } \\
\text { processos }\end{array}$ & $\begin{array}{l}\text { Atrasos no funcionamento operacional da } \\
\text { tecnologia transferida e no ajuste de } \\
\text { máquinas e equipamentos com grande } \\
\text { influência negativa na qualidade do } \\
\text { produto final. }\end{array}$ & $\begin{array}{l}\text { Falha no dimensionamento e manutenção } \\
\text { de atividades técnicas no momento } \\
\text { adequado, além de instalações industriais e } \\
\text { instruções de trabalho inadequadas. }\end{array}$ \\
\hline $\begin{array}{l}\text { Especificações } \\
\text { de projeto de } \\
\text { produto }\end{array}$ & $\begin{array}{l}\text { Dificuldades na fabricação e venda do } \\
\text { produto original, conforme fabricado no } \\
\text { Brasil (materiais, características e } \\
\text { métodos de produção). }\end{array}$ & $\begin{array}{l}\text { Falta de adaptações no projeto do produto, } \\
\text { considerando a localização do produto no } \\
\text { país destino da tecnologia. }\end{array}$ \\
\hline
\end{tabular}

Revista Produção Online, Florianópolis, SC, v.12, n. 4, p. 944-971, out./dez. 2012. 
Após o detalhamento dos impactos e suas causas, foram analisadas se as causas seriam passíveis de controle pela empresa, ou seja, se elas poderiam ter sido atenuadas ou eliminadas. Analisando as situações em campo, em conjunto com os membros das empresas estudadas, constatou-se que todas as causas identificadas seriam passíveis de controle. Baseado nesse pressuposto, foram delineadas algumas diretrizes que poderiam contribuir com a prevenção ou contorno dessas causas, em conjunto com os participantes do estudo.

\section{CONJUNTO DE DIRETRIZES PARA A TRANSFERÊNCIA DE TECNOLOGIA NO MEIO INDUSTRIAL}

Apesar de terem sido selecionadas quatorze variáveis que geravam impactos relevantes nesse caso, associadas à quatorze causas, apenas onze diretrizes foram delimitadas em função de algumas delas impactarem em mais de uma variável, como é o caso da diretriz que recomenda uma "análise prévia das normas locais", por exemplo, que envolve as leis regionais referentes à importação, exportação, leis trabalhistas, salários, dias festivos, impostos e fatores econômicos. Considerando que envolve muitos fatores, essa diretriz contribui para evitar ou amenizar até cinco variáveis. Todas as diretrizes foram resultantes de discussões conjuntas, envolvendo pesquisadores e funcionários envolvidos no PTT, além de se basear nas revisões apresentadas. As onze diretrizes são descritas a seguir:

Diretriz 01 (Estudo preliminar) - Estudo do mercado receptor da tecnologia: Realizar um estudo prévio de mercado para verificar a compatibilidade e aceitabilidade do produto a ser produzido com o padrão e necessidades do mercado onde será implantada a nova tecnologia. Esse estudo visa prever as necessidades relacionadas às especificações do projeto do produto, mostrando se o produto a ser produzido necessita de adaptações ou mudanças no projeto detentor da tecnologia original. Esse procedimento evita que a nova tecnologia produza um produto destinado ao fracasso ou desencadeie a necessidade de alterações posteriores ao PTT. Essa diretriz contribui para amenizar a variável "Especificações de projeto de produto".

Revista Produção Online, Florianópolis, SC, v.12, n. 4, p. 944-971, out./dez. 2012. 
Diretriz 02 (Análise energética): Esse estudo visa evitar atrasos e gastos emergenciais para que a tecnologia transferida (máquinas e equipamentos) funcione normalmente. Esse estudo deve ser realizado antes de qualquer equipamento ser preparado para a transferência. Após o estudo da demanda energética necessária, deve-se realizar as mudanças necessárias a fim de alcançar um ponto ideal de consumo energético pela empresa. Com os dados ideais de consumo energético, realiza-se um comparativo de demanda energética entre a região emissora e a região receptora da tecnologia, realizando possíveis adaptações locais no receptor, antes da chegada da nova tecnologia. Essas adaptações podem incluir a previsão de futuras ampliações. Essa diretriz contribui para amenizar 4 variáveis: Infra estrutura fabril, Engenharia de processos, Suprimento energético e Custos industriais.

Diretriz 03 (Análise de normas): Conhecer as leis regionais no receptor da tecnologia referentes à importação, exportação, leis trabalhistas, salários, dias festivos, impostos e fatores econômicos. O levantamento dessas informações tem por objetivo prever:

^ Os atrasos e gastos extras relacionados com as leis locais de importação e exportação de matéria prima, máquinas e equipamentos;

^ Os gastos e problemas operacionais relacionados com o pagamento de horas extras e férias, que podem ser diferentes dos contabilizados na região emissora de tecnologia;

A Fatores operacionais locais relacionados às leis trabalhistas que possam interferir nas atividades de implantação, manutenção e operação da tecnologia transferida.

Essa diretriz contribui para amenizar 5 variáveis: Logística interna e Controle de estoques, Logística externa, Normas e regulamentos da região, Mão de obra (cultura local) e Custos Industriais.

Diretriz 04 (Análise de idiomas e nível educacional): Realizar um levantamento do idioma da região receptora de tecnologia e uma lista de escolas, universidades e centros tecnológicos e de treinamentos, visando traçar um perfil do tipo de Revista Produção Online, Florianópolis, SC, v.12, n. 4, p. 944-971, out./dez. 2012. 
qualificação profissional disponível na região receptora da tecnologia. Esse estudo objetiva evitar:

¿ Operação e desenvolvimento precário da tecnologia ou instruções de trabalho mal traduzidas devido à falta de capacitação técnica adequada na região receptora da tecnologia;

A Atrasos na manutenção de máquinas e equipamentos transferidos de outros países, provocados por instruções técnicas em idiomas diferentes ao da região receptora da tecnologia;

A Dificuldades no planejamento de treinamentos complementares para suprir deficiências em conhecimentos demandados pela tecnologia transferida.

Essa diretriz contribui para amenizar 2 variáveis: Idioma e Educação.

Diretriz 05 (Análise logística e de fornecedores): Levantamento da capacidade de fornecimento de empresas instaladas na região receptora e emissora da tecnologia e em região distinta das duas, para que haja uma alternativa adicional caso as duas anteriores não possam atender às especificações de projeto. $\mathrm{O}$ mesmo estudo deve ser realizado para empresas de transporte/logística e aquelas relacionadas à importação e exportação de bens, máquinas e insumos. Esse estudo deve conter:

A Lista de empresas de matéria prima primária, tipo de matéria prima a que estão relacionadas, localização, contatos e proximidade com a unidade receptora de tecnologia;

^ Lista de empresas prestadoras de serviços, tipos de serviços a que estão relacionadas, localização, contatos e proximidade com a unidade receptora de tecnologia;

A Lista de empresas de transportes terrestre, marítimo e aéreo;

A Lista de empresas relacionadas à prestações de serviços, incluindo suas capacitações, localizações e proximidades com a unidade receptora de tecnologia;

^ Levantamento de custos gerais de matéria prima, máquinas, equipamentos e serviços demandados pela tecnologia transferida na região receptora. Revista Produção Online, Florianópolis, SC, v.12, n. 4, p. 944-971, out./dez. 2012. 
Essas atividades visam eliminar:

A Atrasos para o início das operações do PTT devido à falta de matéria prima (local e importada);

A Atrasos no processo geral devido à falta de fluxo logístico (nacional e internacional);

^ Custos adicionais devido às importações de matéria prima, máquinas e equipamentos em caráter de urgência.

Essa diretriz contribui para amenizar 4 variáveis: Logística interna (México) e controle de estoques, Logística externa (Importação/Exportação), Rede local de fornecedores e Custos industriais.

Diretriz 06 (Engenharia do produto): Estudo detalhado sobre os produtos finais a serem fabricados pela tecnologia transferida no receptor. Esse estudo deve conter:

A Projeto do produto, com especificações técnicas incluindo cálculos, desenhos, características do material e especificações sobre o descarte do produto nos idiomas da região emissora e receptora da tecnologia;

A Especificações do processo de fabricação e manutenção do produto, incluindo ferramentas necessárias nos idiomas das duas regiões. Incluir os custos de matéria prima e fabricação que se tem como referência no emissor da tecnologia;

A Especificações logísticas do produto, incluindo tipos de embalagem, modos de armazenagem, tipos de transportes para a entrega do produto ao cliente e outros.

As atividades descritas nessa diretriz têm o propósito de:

A Reduzir falhas técnicas e de qualidade no produto final;

^ Adaptar o produto final à realidade local;

^ Evitar atrasos relativos à falta de matéria prima requisitada no receptor de tecnologia;

« Tornar possível o desenvolvimento do receptor de tecnologia, incluindo peças, máquinas e equipamentos, visando à melhoria do processo ou manutenção técnica da tecnologia recebida. 
Essa diretriz contribui para amenizar 3 variáveis: Qualidade industrial, Engenharia de processos e especificações de projeto de produto.

Com essas diretrizes, os impactos das variáveis que mais obstruem um PTT e as suas respectivas causas são evitados em sua grande maioria, pois as 14 variáveis previamente citadas no Quadro 4 foram consideradas ao se formular as diretrizes previamente citadas.

Entretanto, com o objetivo de considerar outros fatores que, segundo a análise do grupo envolvido com o estudo teórico e com o caso prático de TT, também impactam nessas variáveis, outras diretrizes foram formuladas. São elas:

Diretriz 07 (Análise de custos industriais): Identificação de custos no receptor da tecnologia relacionados à:

A Logística (importação, exportação e transporte terrestre local);

^ Salários;

A Impactos culturais (educação, feriados locais e outros). A falta de nível técnico e/ou superior gera problemas na operação e manutenção de equipamentos e maior tempo de aprendizado para efetuar as tarefas. Feriados prolongados afetam o planejamento logístico e produtivo, causando impacto nos custos finais do produto;

A Máquinas, equipamentos e Matéria prima necessários;

A Ferramentas e equipamentos de segurança fabril;

A Insumos básicos como energia elétrica, água, telefonia e internet;

A Serviços terceirizados relacionados às instalações fabris (rede pneumática e elétrica, equipamentos para movimentação de máquinas pesadas, modificações de construções civis e outras necessidades demandadas).

Esse levantamento visa reduzir gastos não previstos relacionados às: compras adicionais, contratações de serviços e atividades de emergência. Além disso, também visa prever os impactos sociais e culturais que, quando desconsiderados, afetam a tecnologia implantada ou o processo de implantação. Sendo assim, essa diretriz contribui para amenizar a variável "Custos industriais". 
Diretriz 08 (Análise do processo na fábrica): Relatório técnico sobre os requisitos industriais contendo:

A Layout fabril;

¿ Lista de máquinas, equipamentos e ferramentas necessárias para a instalação, operação e manutenção da tecnologia transferida;

4 Instruções de trabalho completas no idioma do receptor de tecnologia;

^ Características técnicas gerais das instalações da emissora e da receptora da tecnologia.

Esse estudo visa eliminar atrasos e gastos não planejados com a construção, operação e manutenção da tecnologia física (máquinas e equipamentos) em um local desconhecido.

Essa diretriz contribui para amenizar 2 variáveis: Infra estrutura fabril e Engenharia de processos.

Diretriz 09 (Qualidade industrial): Requisitos da qualidade exigidos para o produto a ser fabricado com a tecnologia transferida que devem conter:

A Requisitos principais exigidos pelo cliente que devem ser atendidos pelo produto resultante da tecnologia transferida;

A Estabelecimento de política e sistema de gestão da qualidade que atuem na tecnologia transferida;

A Envolvimento da receptora na política da qualidade que a tecnologia transferida requer.

Essas atividades visam contribuir para que o produto atenda às expectativas do cliente para o qual foi projetado, resultando em um PTT bem sucedido. Essa diretriz contribui para amenizar a variável "Qualidade industrial".

Diretriz 10: Elaboração de um plano de ação. Esse plano deve conter as atividades, pessoas envolvidas e suas respectivas responsabilidades, prazos e cronogramas, contemplando o início, o desenvolvimento e as atividades finais do PTT. Essa diretriz contribui para melhorar o controle do processo de desenvolvimento do produto. 
Diretriz 11: Registros das lições aprendidas para consultas e aplicações. Registrar as fases do PTT, problemas, soluções e resultados, compondo um histórico que possa ser consultado e aproveitado em experiências futuras, formando um banco de dados de "lições aprendidas".

As duas diretrizes finais possuem relação com todas as variáveis geradoras de impacto porque se referem ao controle e histórico de todas as atividades relacionadas à um PTT. O Quadro 6 apresenta um resumo das onze diretrizes a serem aplicadas antes de se iniciar um PTT.

Quadro 6 - Resumo das onze diretrizes propostas (Continua)

\begin{tabular}{|c|c|}
\hline Diretrizes & $\begin{array}{l}\text { Itens a serem levantados em campo no emissor e/ou no receptor da } \\
\text { tecnologia }\end{array}$ \\
\hline $\begin{array}{l}\text { Diretriz } 01 \text { (Estudo } \\
\text { preliminar) }\end{array}$ & $\begin{array}{l}\text { - Verificar a compatibilidade e aceitabilidade do produto a ser produzido } \\
\text { com o padrão e necessidades do mercado onde será implantada a nova } \\
\text { tecnologia. }\end{array}$ \\
\hline $\begin{array}{l}\text { Diretriz } 02 \text { (Análise } \\
\text { energética) }\end{array}$ & $\begin{array}{l}\text { - Estudo da demanda energética necessária; } \\
\text { - Comparativo de demanda energética entre a região emissora e a região } \\
\text { receptora da tecnologia; } \\
\text { - Identificações da necessidade de adaptações locais no receptor, } \\
\text { incluindo a previsão de futuras ampliações. }\end{array}$ \\
\hline $\begin{array}{c}\text { Diretriz } 03 \text { (Análise de } \\
\text { normas) }\end{array}$ & $\begin{array}{l}\text { - Conhecer as leis regionais no receptor da tecnologia referente à: } \\
\text { importação, exportação, leis trabalhistas, salários, dias festivos, impostos } \\
\text { e fatores econômicos. }\end{array}$ \\
\hline $\begin{array}{l}\text { Diretriz } 04 \text { (Análise de } \\
\quad \text { idiomas e nível } \\
\quad \text { educacional) }\end{array}$ & $\begin{array}{l}\text { - Identificar o idioma da região receptora; } \\
\text { - Levantar as escolas, universidades, centros tecnológicos e de } \\
\text { treinamentos para traçar um perfil do tipo de qualificação profissional na } \\
\text { região receptora. }\end{array}$ \\
\hline $\begin{array}{l}\text { Diretriz } 05 \\
\text { (Rede logística e de } \\
\text { fornecedores) }\end{array}$ & $\begin{array}{l}\text { Identificar e relacionar os seguintes itens: } \\
\text { - Capacidade de fornecimento de empresas instaladas na região receptora } \\
\text { e emissora da tecnologia e em região distinta das duas (relacionando o } \\
\text { tipo de matéria prima ou serviço, localização, contatos e proximidades } \\
\text { com a unidade receptora); } \\
\text { - Empresas de transportes terrestre, marítimo e aéreo; } \\
\text { - Empresas de importação e exportação de bens, máquinas e insumos; } \\
\text { - Para todas deve ser relacionado o tipo da empresa quanto à (matéria } \\
\text { prima/serviço/transporte, localização, contatos e proximidade com a } \\
\text { unidade receptora de tecnologia); }\end{array}$ \\
\hline $\begin{array}{c}\text { Diretriz } 06 \text { (Engenharia } \\
\text { do produto) }\end{array}$ & $\begin{array}{l}\text { Especificações técnicas do produto, do processo de fabricação e de } \\
\text { como enviar para o cliente nos idiomas das regiões emissora e receptora } \\
\text { de tecnologia, incluindo: } \\
\text { - Projeto detalhado completo (com desenhos, cálculos, materiais, } \\
\text { descarte); } \\
\text { - Especificações do processo de fabricação e manutenção do produto } \\
\text { (com ferramentas necessárias, custo referencial de matéria prima e } \\
\text { fabricação do emissor da tecnologia); } \\
\text { - Especificações logísticas do produto (tipo de embalagem, armazenagem, } \\
\text { transportes para a entrega e outros). }\end{array}$ \\
\hline
\end{tabular}




\begin{tabular}{|c|c|}
\hline Diretrizes & $\begin{array}{l}\text { Itens a serem levantados em campo no emissor e/ou no receptor da } \\
\text { tecnologia }\end{array}$ \\
\hline $\begin{array}{l}\text { Diretriz } 07 \text { (Análise de } \\
\text { custos industriais) }\end{array}$ & $\begin{array}{l}\text { Levantamento de custos no receptor da tecnologia relacionados aos } \\
\text { - Seguintes itens: } \\
\text { - Salários e Impactos culturais (formação inadequada para o } \\
\text { desenvolvimento das atividades e feriados); } \\
\text { - Logística (importação, exportação e transporte terrestre local); } \\
\text { - Máquinas, equipamentos e Matéria prima necessários para fabricação, } \\
\text { - Inporte e segurança; } \\
\text { - Serviços relacionados às instrica, água, telefonia e internet); } \\
\text { equipamentos para movimentação de mááquinas pesadas, modificações } \\
\text { de construções civis e outras necessidades demandadas). }\end{array}$ \\
\hline $\begin{array}{l}\text { Diretriz } 08 \text { (Análise do } \\
\text { processo na fábrica) }\end{array}$ & $\begin{array}{l}\text { Relatório técnico sobre os requisitos industriais contendo: } \\
\text { - Layout fabril; } \\
\text { - Lista de máquinas, equipamentos e ferramentas necessárias para a } \\
\text { instalação, operação e manutenção da tecnologia transferida; } \\
\text { - Características técnicas das instalações da emissora e receptora da } \\
\text { tecnologia; } \\
\text { - Instruções de trabalho no idioma do receptor da tecnologia. }\end{array}$ \\
\hline $\begin{array}{l}\text { Diretriz } 09 \text { (Qualidade } \\
\text { industrial) }\end{array}$ & $\begin{array}{l}\text { Requisitos da qualidade locais exigidos para o produto, envolvendo: } \\
\text { - Requisitos exigidos pelo cliente que devem ser atendidos com o produto; } \\
\text { - Estabelecimento de política e sistema de gestão da qualidade da } \\
\text { tecnologia transferida; } \\
\text { - Envolvimento da receptora na política de qualidade que a tecnologia } \\
\text { transferida requer. }\end{array}$ \\
\hline $\begin{array}{c}\text { Diretriz } 10 \\
\text { (Plano de ação) }\end{array}$ & $\begin{array}{l}\text { - Elaboração de plano de ação contendo: as atividades, as pessoas e } \\
\text { suas respectivas responsabilidades, os prazos e cronogramas, } \\
\text { contemplando o início, o desenvolvimento e as atividades finais do PTT. }\end{array}$ \\
\hline $\begin{array}{l}\text { Diretriz } 11 \text { (Lições } \\
\text { aprendidas) }\end{array}$ & $\begin{array}{l}\text { - Registro histórico para futuras consultas dos seguintes itens: } \\
\text { desenvolvimento detalhado das etapas e fases do PTT, incluindo } \\
\text { problemas, soluções e resultados encontrados. }\end{array}$ \\
\hline
\end{tabular}

Para avaliar o efeito das onze diretrizes propostas, foi realizada uma aplicação simulada, estimando o que poderia ter sido evitado ou minimizado se elas tivessem sido aplicadas antes do início do PTT entre as empresas estudadas. Tal simulação foi possível em função do arquivamento de dados de desempenho durante todas as fases do PTT, os quais foram coletados durante e após o PTT, com informações relacionadas aos custos, tempo, receita de vendas e outros. O Quadro 7 mostra uma análise comparativa entre os resultados obtidos sem a utilização das diretrizes propostas e com a simulação da aplicação dessas diretrizes. Para comparar os resultados foram identificadas, previamente, oito fases principais, considerando do início ao final do PTT realizado, em comum acordo com os envolvidos na pesquisa e no estudo de campo, que estavam participando da TT desde o seu início. 
Quadro 7 - Quadro comparativo entre os resultados da utilização e da não utilização das diretrizes

\begin{tabular}{|c|c|c|}
\hline $\begin{array}{l}\text { Fases realizadas } \\
\text { durante o PTT }\end{array}$ & $\begin{array}{l}\text { Sem o uso das diretrizes } \\
\text { (resultados reais) }\end{array}$ & $\begin{array}{l}\text { Com o uso das diretrizes } \\
\text { (resultados simulados) }\end{array}$ \\
\hline $\begin{array}{l}\text { Estabelecimento de } \\
\text { estrutura energética } \\
\text { para tecnologia física } \\
\text { (máquinas e } \\
\text { equipamentos) }\end{array}$ & $\begin{array}{l}\text { Gastos extras com novas instalações, } \\
\text { geradores, redes, adaptações e outros } \\
\text { fatores energéticos de alto custo, não } \\
\text { previstos no processo. }\end{array}$ & $\begin{array}{l}\text { Planejamento de recursos técnicos e } \\
\text { financeiros demandados para a } \\
\text { estrutura da tecnologia, com a } \\
\text { possibilidade de executar alterações } \\
\text { prévias no processo, nas instalações } \\
\text { ou na própria tecnologia, sem gastos } \\
\text { extras. }\end{array}$ \\
\hline $\begin{array}{l}\text { Aquisição de } \\
\text { máquinas e } \\
\text { equipamentos }\end{array}$ & $\begin{array}{l}\text { Compra de máquinas e equipamentos } \\
\text { iguais aos da matriz emissora, com } \\
\text { riscos de não compatibilidade com o } \\
\text { receptor, acarretando gastos extras. }\end{array}$ & $\begin{array}{l}\text { Melhor dimensionamento de } \\
\text { máquinas e equipamentos que } \\
\text { atendam às necessidades do } \\
\text { receptor, com a criação de soluções } \\
\text { alternativas de baixo custo que os } \\
\text { dimensionados para a matriz } \\
\text { emissora de tecnologia. }\end{array}$ \\
\hline $\begin{array}{l}\text { Aquisição de matéria } \\
\text { prima para o } \\
\text { funcionamento da } \\
\text { tecnologia } \\
\text { transferida }\end{array}$ & $\begin{array}{l}\text { Compra de matéria prima, em sua } \\
\text { maioria, da matriz, com incrementos de } \\
\text { impostos de importação. } \\
\text { Falta de adequação técnica de algumas } \\
\text { matérias-primas (tipo químico) às } \\
\text { características geográficas e ao clima da } \\
\text { região do receptor, gerando custos com } \\
\text { especialistas para adequação do } \\
\text { processo. }\end{array}$ & $\begin{array}{l}\text { Dimensionamento prévio de matéria } \\
\text { prima em quantidade e } \\
\text { características técnicas necessárias } \\
\text { para o receptor de tecnologia. Real } \\
\text { dimensionamento de gastos de } \\
\text { matéria prima importada. }\end{array}$ \\
\hline Instalações fabris & $\begin{array}{l}\text { Construção não prevista de estruturas } \\
\text { para receber a tecnologia, muitas delas } \\
\text { construídas somente após a chegada de } \\
\text { máquinas e equipamentos, gerando } \\
\text { custos não programados e atrasos no } \\
\text { inicio das operações. }\end{array}$ & $\begin{array}{l}\text { Construção de instalações fabris } \\
\text { para a nova tecnologia, com custos } \\
\text { previamente estimados, } \\
\text { considerando os fatores do receptor } \\
\text { da tecnologia. }\end{array}$ \\
\hline $\begin{array}{l}\text { Instruções de } \\
\text { trabalho, operação e } \\
\text { manutenção }\end{array}$ & $\begin{array}{l}\text { Instruções de trabalho, operação e } \\
\text { manutenção incompletas ou ineficientes, } \\
\text { decorrentes de diferenças de idioma, } \\
\text { culturais, educacionais ou sociais, } \\
\text { atrasando e prejudicando o } \\
\text { desenvolvimento da tecnologia } \\
\text { transferida. }\end{array}$ & $\begin{array}{l}\text { Instruções de trabalho, operação e } \\
\text { manutenção adaptadas e/ou criadas } \\
\text { de acordo com as características do } \\
\text { receptor, evitando problemas de } \\
\text { manutenção e/ou operação de má } \\
\text { qualidade pelos envolvidos no } \\
\text { processo. }\end{array}$ \\
\hline $\begin{array}{l}\text { Produção dos lotes } \\
\text { iniciais, resultantes } \\
\text { da tecnologia } \\
\text { transferida }\end{array}$ & $\begin{array}{l}\text { Incompatibilidade de aspectos técnicos } \\
\text { como matéria prima, requisitos de } \\
\text { mercado, custos locais, entre outros } \\
\text { fatores, afetando a produtividade, os } \\
\text { custos a qualidade do produto final. }\end{array}$ & $\begin{array}{l}\text { Domínio do produto final, permitindo } \\
\text { a previsão de matéria prima, a } \\
\text { adequação do processo e dos } \\
\text { recursos envolvidos, necessários } \\
\text { para atender o consumidor local. }\end{array}$ \\
\hline $\begin{array}{l}\text { Planejamento de } \\
\text { investimentos no } \\
\text { processo de } \\
\text { transferência de } \\
\text { tecnologia }\end{array}$ & $\begin{array}{l}\text { Planejamento ineficiente quanto aos } \\
\text { custos envolvidos durante um PTT. }\end{array}$ & $\begin{array}{l}\text { Planejamento completo sobre os } \\
\text { custos gerados durante um PTT, } \\
\begin{array}{l}\text { abrangendo, inclusive, fatores } \\
\text { emergenciais quando necessários. }\end{array}\end{array}$ \\
\hline $\begin{array}{l}\text { Fabricação inicial do } \\
\text { produto para venda } \\
\text { no receptor da } \\
\text { tecnologia }\end{array}$ & $\begin{array}{l}\text { Produto final com atendimento parcial } \\
\text { dos requisitos demandados pelo cliente, } \\
\text { gerando custos extras para adaptações } \\
\text { do produto, que impactaram em } \\
\text { alterações no processo e treinamento de } \\
\text { funcionários. }\end{array}$ & $\begin{array}{l}\text { Produto final atendendo grande parte } \\
\text { dos requisitos demandados pelo } \\
\text { cliente (receptor da tecnologia), } \\
\text { evitando adaptações no produto com } \\
\text { gastos extras. }\end{array}$ \\
\hline
\end{tabular}

Revista Produção Online, Florianópolis, SC, v.12, n. 4, p. 944-971, out./dez. 2012. 
Como pode ser visto, muitos gastos e dificuldades teriam sido evitados se as diretrizes tivessem sido aplicadas previamente ao PTT, o que mostra o potencial da sua aplicação em campo para esse fim. Entretanto, como já foi comentado anteriormente, as variáveis mais impactantes podem variar de um caso para outro, refletindo, consequentemente, nas diretrizes a serem tomadas.

\section{CONCLUSÕES}

Esse estudo se propôs a apresentar diretrizes preventivas para minimizar os problemas resultantes de um PTT entre empresas industriais da América Latina. Para isso, identificou a presença de quatorze variáveis que tendem a desencadear impactos comprometedores na eficácia de um PTT, baseadas na teoria e em um caso prático de TT entre empresas industriais situadas no Brasil (emissor) e no México (receptor). As variáveis são: Qualidade industrial, Logística interna (México) e Controle de estoques, Logística externa (Importação/ Exportação), Rede local de fornecedores, Infra estrutura fabril, Controle de estoque, Engenharia de processos, Especificações de projeto de produto, Normas e regulamentos da região, Suprimento energético, Idioma, Mão de obra (cultura local), Custos industriais e Educação. Através dessa relação de variáveis, os impactos desencadeados por elas e quais seriam as causas desses impactos foram delimitados. Analisando as causas, foram delineadas seis diretrizes para eliminar, controlar ou minimizar as quatorze variáveis apresentadas. Além dessas seis diretrizes, foram delimitadas mais cinco diretrizes complementares, visando considerar outros fatores que também afetam um PTT. Sendo assim, onze diretrizes foram apresentadas nesse trabalho, cuja utilização foi simulada para o caso prático de TT estudado. As resultantes reais do caso prático, quando as empresas encerraram a TT após um ano, foram comparadas com os resultados simulados, caso as empresas tivessem planejado o PTT com a utilização dessas onze diretrizes. Constatou-se que as diretrizes orientariam as empresas em vários aspectos, evitando gastos desnecessários, tempos excessivos e atendendo o cliente local com mais qualidade, sem demandar alterações posteriores. 
Entretanto, é importante ressaltar que, estudos similares, envolvendo empresas situadas em países distintos da combinação (Brasil-México), precisariam ser reavaliados, considerando que em outras realidades o conjunto de impactos mais relevantes poderia variar, não coincidindo, necessariamente, com os listados nesse estudo. Em função dessa variabilidade, outras diretrizes precisariam ser delimitadas, visando atender o novo PTT. Outros detalhes desse estudo podem ser vistos na dissertação de mestrado de Rodrigues (2008).

Nota:

Trabalho resultante de dissertação de mestrado

\section{REFERÊNCIAS}

ABEYSEKERA, J. D. A. Views on the future of ergonomics: ergonomics and technology transfer. International Journal of Industrial Ergonomics. Amsterdam, v.5, p.181-184,1990.

ALBINO, V.; GARAVELLI, A. C.; SCHIUMA, G. Knowledge transfer and inter-firm relationships in industrial districts: the role of the leader firm. Technovation, v. 19, p. 53-63, 1999.

ARGABRIGHT, G. C. Using technology transfer to improve safety and health. Professional Safety. St. Joseph, v. 44, n. 9, p. 28-32, 1999.

CARVALHO, M. F. H.; RODRIGUES, E. O; CONTADOR, J. C. Metodologia para constituição de parceria entre empresas. Produção On Line, v. 7, n.1, p. 184-206, 2007.

COHEN, G. Technology transfer: strategic management in developing countries. 1 . ed. Thousand Oaks: Sage publications Inc., 2004. 337p.

CYSNE, F. P. Transferência de tecnologia entre a universidade e a indústria. Revista eletrônica de biblioteconomia e ciência da informação. Florianópolis: UFSC, n. 20, 2o semestre. Disponível em: <http://www.encontrosbibli.ufsc.br/Edicao 20/4 cysne.pdf> Acesso em: 14 jul. 2006.

DUTRA, A. R. A. Análise de custo/benefício na transferência de tecnologia: estudo de caso utilizando a abordagem antropotecnológica. Tese (Doutorado em Engenharia de Produção) - Universidade Federal de Santa Catarina, Florianópolis, 1999.

EDEN, C.; HUXHAM, C. Pesquisa-ação no estudo das organizações. In CLEGG, S. R., HARDY, C. AND NORD, W. R. (Ed.), Handbook de estudos organizacionais. Revista Produção Online, Florianópolis, SC, v.12, n. 4, p. 944-971, out./dez. 2012. 
São Paulo, SP: Atlas, 2001. p. 93-117.

ERENSAL, Y. C.; ALBAYRAK, Y. E. Transferring appropriate manufacturing technologies for developing countries. Journal of Manufacturing Technology Management, v. 19, p. 158-171, 2007.

FAROOQ, S. AND O'BRIEN, C. Risk calculations in the manufacturing technology selection process. Journal of Manufacturing Technology Management, v. 21, p. 28-49, 2009.

FRANK, A. G.; ECHEVESTE, M. E. Barreiras de transferência de conhecimento entre projetos de produtos. Produção On Line, v. 11, n. 1, p. 29-53, 2011.

GALLAHER, M.; DELHOTAL, K. C. Modeling the impact of technical change on emissions abatement investments in developing countries. Journal of Technology Transfer, v.30, n.4, p. 211-225, 2005.

GREINER, M. A; FRANZA, R. M. Barriers and bridges for successful environmental technology transfer. Journal of Technology Transfer. Chicago, v.28, n. 2, p.167177, 2003.

GURR, K.; STRAKER, L.; MOORE, P. Cultural hazards in the transfer of ergonomics technology. International Journal of Industrial Ergonomics, v.22, p.397-404, 1998.

HEMAIS, C. A.; BARROS, H. M.; ROSA, E. O.R. Technology competitiveness in emerging markets: the case of the Brazilian polymer industry. Journal of Technology Transfer, v.30, p.303-314, 2005.

HESLOP, L. A.; MCGREGOR, E.; GRIFFITH, M. Development of a technology readiness assessment measure: the cloverleaf model of technology transfer. Journal of Technology Transfer, v.26, n.4, p.369-384, 2001.

ICS UNIDO - INTERNATIONAL CENTRE FOR SCIENCE AND HIGH TECHNOLOGY. Area Science Parl Padriciano. Methodology for the preparation and preliminary evaluation of technology transfer projects. Trieste. 2005. $32 \mathrm{p}$.

JABAR, J.; SOOSAY, C.; SANTA, R. Organizational learning as an antecedent of technology transfer and new product development: A study of manufacturing firms in Malaysia. Journal of Manufacturing Technology Management, v. 22, p. 25-45, 2010.

JIANG, C. A re-examination of technology transfer in sino-foreign joint ventures after China's WTO accession. Journal of American Academy of Business. Cambridge, v.9, p.133, 2006.

KREMIC, T. Tecnology transfer: a contextual approach. Journal of Technology Transfer, v.28, n.2, p.149-158, 2003. 
LINDGREN, R.; HENFRIDSSON, O.; SCHULTZE, U. Design Principles for Competence Management Systems: a Synthesis of an Action Research Study. MIS Quarterly, v.28, n.3, 2004.

LUNDQUIST, G. A rich vision of technology transfer technology value management. Journal of Technology Transfer. Chicago, v. 28, n. 3-4, p. 265-283, 2003.

MESHKATI, N. Technology transfer to developing countries: a tripartite micro-and macroergonomic analysis of human-organization-technology interfaces.

International Journal of Industrial Ergonomics, v.4, p.101-115, 1989.

PETRONI, G.; VERBANO, C. The development of a technology transfer strategy in the aerospace industry: the case of the Italian Space Agency. Technovation, v. 20, p. 345-351, 2000.

RAHMAN, A. A.; BENNETT, D. Advanced manufacturing technology adoption in developing countries: the role of buyer-supplier relationships. Journal of Manufacturing Technology Management, v. 20, p. 1099-1118, 2009.

RODRIGUES, F. R. M. Diretrizes para minimizar os impactos negativos de um processo de transferência de tecnologia: um estudo de caso Brasil-México, Dissertação (Mestrado em Engenharia) - PPGEM, UTFPR, Brasil, 2008.

ROGERS, E. M. The nature of technology transfer. Science communication. Thousand Oaks, v. 23, n. 3, p. 323-341, 2002.

STRINGER, E. T. Action Research: a Handbook for Practitioners. Sage, 1996.

TAKAHASHI, V. P. Transferência de conhecimento tecnológico: estudo de múltiplos casos na indústria farmacêutica. Gestão \& Produção, São Carlos, v.12, n. 2, p. 255269, 2005.

THIOLLENT, M. Pesquisa-ação nas organizações. São Paulo: Atlas, 1997.

WISNER, A. A inteligência no trabalho: textos selecionados de ergonomia. 1. ed. São Paulo: Fundacentro. 191p., 1994.

ZENNER, T. (2001). Preparing for successful design transfer. Disponível em: <http://www.devicelink.com/mddi/archive/01/08/007.html>. Acesso em: 02 jun. 2007.

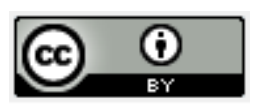

Artigo recebido em 23/04/2011 e aceito para publicação em 07/05/2012. 